\title{
Inhibition of Stearoyl-CoA Desaturase-1 Activity Suppressed SREBP Signaling in Colon Cancer Cells and Their Spheroid Growth
}

\author{
Xian-Yang Qin * and Soichi Kojima \\ Liver Cancer Prevention Research Unit, RIKEN Center for Integrative Medical Sciences, Wako, \\ Saitama 351-0198, Japan; skojima@riken.jp \\ * Correspondence: xyqin@riken.jp; Tel.: +81-48-467-7938
}

Received: 28 December 2018; Accepted: 23 January 2019; Published: 26 January 2019

check for updates

\begin{abstract}
Unsaturated fatty acids are critical in promoting colon tumorigenesis and its stemness. Stearoyl-CoA desaturase-1 (SCD1) is a rate-limiting lipid desaturase associated with colon cancer cell proliferation and metastasis control. This study aims to evaluate the effects of SCD1 inhibition on colon cancer spheroid growth in a three-dimensional cell culture system. An analysis of clinical data showed that increased SCD1 gene expression in colon tumors was negatively correlated with the prognosis. A chemical inhibitor of SCD1, CAY10566, inhibited the growth of colon cancer cells in both monolayer and sphere cultures. In addition, oleic acid administration-a monounsaturated fatty acid generated by the action of SCD1 - prevented the suppression of sphere formation by CAY10566. RNA-sequencing data from 382 colon tumor patient samples obtained from the Cancer Genome Atlas database showed that 806 genes were SCD1-associated genes in human colon cancer. Correlation analysis identified the master regulator of lipid homeostasis sterol regulatory element-binding protein 2 (SREBP2) as a prominent transcription factor, whose expression was positively correlated with $S C D 1$ in human colon cancer. SCD1 knockdown using siRNA in colon cancer samples, suppressed SREBP2 gene expression, providing direct evidence that SREBP signaling is under the control of SCD1 in these cells. Pathway analysis in the Ingenuity Pathways Analysis platform showed that SCD1 expression positively correlated with genes involved in multiple pathways, including lipid synthesis and incorporation, cell proliferation, and tissue tumorigenesis. Further network analysis revealed a central role for Myc in the network hierarchy of the SCD1-correlated genes. These findings suggested that SCD1 inhibition would be an effective strategy for suppressing colon cancer spheroid growth, partly through downregulating SREBP-mediated lipid and cholesterol metabolism and Myc signaling.
\end{abstract}

Keywords: stearoyl-CoA desaturase-1; colon cancer; spheroid culture; fatty acid; sterol regulatory element-binding protein 2

\section{Introduction}

Colon cancer, a well-characterized inflammation-driven disease, is the third leading cause of cancer-related deaths worldwide, with more than one million new cases reported each year [1]. These outcomes are mainly due to its poor prognosis, where long term treatment leads to patients acquiring resistance to therapy. In China, according to the data of a population-based cancer registry, the age-standardized 5-year relative survival rate for colon cancer is less than 50\% [2]. The major cause of colon cancer therapy failure is the emergence of tumor-driving cells or cancer stem cells (CSCs), which possess high plasticity and a mesenchymal-like phenotype [3]. Among these contributors, leucine-rich-repeat-containing G-protein-coupled receptor $5(\mathrm{Lgr} 5)^{+}$colon stem cells, existing near the 
base of intestinal crypts that normally contribute to all cell lineages in the intestinal epithelium, are the most rapidly self-renewing epithelial tissues in mammals [4] and are known to serve as a cell of origin for colon cancer due to their inherent plasticity and longevity [5]. Therefore, new therapies based on understanding the molecular mechanisms underlying colon CSC regulation are needed.

There is growing evidence associating colon cancer development with environmental causes, such as a high-fat diet [6]. Pro-obesity diets enhance the numbers and function of the Lgr5 ${ }^{+}$ stem cells and/or colon tumorigenesis by activating multiple pathways, including peroxisome proliferator-activated receptor delta (PPAR- $\delta$ ) and Wnt/ $\beta$-catenin signatures [7], retinol binding protein 4 (RBP4)-stimulated by the retinoic acid 6 (STRA6) pathway [8], and fatty acid oxidation [9]. Similar changes were observed when dietary constituents, such as palmitic acid and oleic acid (OA), were administered, suggesting a critical role for fatty acid in the maintenance of colon CSCs.

Fatty acids function as critical constituents of membrane structure, large energy sources, and serve as signal mediators for signal transduction [10]. Stearoyl-CoA desaturase-1 (SCD1), a transmembrane protein predominantly located at the endoplasmic reticulum, is a rate-limiting lipid desaturase responsible for generating monounsaturated fatty acids, mainly palmitoleic acid and OA [11]. We recently showed that SCD1 is upregulated in CSC-like cell populations compared with non-CSC populations in human liver cancer cell lines $[12,13]$. Other studies also shed light on the roles of unsaturated fatty acids in maintaining CSC stemness by activating nuclear factor kappa-light-chain-enhancer of activated B cells (NF-kB) [14] and Wnt- $\beta$-catenin [15] signaling pathways. These studies indicate that lipid desaturation is a metabolic signature, and SCD1 may be an important therapeutic target in CSCs.

SCD1 has been reported to promote the metastasis of colon cancer by inducing epithelial-mesenchymal transition [16]. Furthermore, the inhibition of SCD1 suppresses colon cancer cell proliferation [17]. Although the underlying molecular mechanism has not been fully understood, possible pathways include either induced ceramide biosynthesis [17] or the depletion of monounsaturated fatty acid [18]. However, a limitation of this study is that in vitro monolayer cell cultures did not mimic in vivo three-dimensional (3D) tumor growth [19]. Therefore, here we focus on the effects of SCD1 inhibition on the spheroid growth potential of a human colon cancer cell line. We employed a simple 3D multicellular tumor spheroid system known to be significantly more resistant to chemotherapeutic agents compared with monolayer cultures [20] and found that a chemical inhibitor of SCD1, CAY10566, efficiently prevented the 3D spheroid formation of colon cancer cells.

\section{Results}

\subsection{Clinical Expression Levels of SCD1}

First, we examined the clinical and prognostic implications of SCD1 expression in human colon cancer. The mining of microarray data from the Gene Expression Omnibus (GEO, accession no. GSE40967) [21] demonstrated that SCD1 gene expression was significantly increased in colon tumors compared with the adjacent non-tumor colon tissues (Figure 1a). Using the PrognoScan database [22], Kaplan-Meier estimates of the proportion of colon cancer patients who survived over 15 years, showed that patients with high SCD1 gene expression in tumors had significantly lower survival rates (Figure 1b). This is in accordance with a recent report, relying on the Cancer Browser database, that colon cancer patients with high SCD1 levels had a poor overall survival rate [16]. These data suggested that SCD1 and lipid desaturation play important tumor-promoting roles in colon cancer.

\subsection{Inhibition of SCD1 Suppresses Sphere Growth of Colon Cancer Cells}

We then examined whether inhibiting lipid desaturation using a chemical inhibitor of SCD1, CAY10566 [14], can suppress the growth of a colon cancer cell line-WiDr cells grown as both monolayers and spheres (Figure 2a). In WiDr monolayers, CAY10566 significantly decreased cell viability (Figure 2b). Similarly, CAY10566 inhibited the spheroid formation in the WiDr 3D culture 
system (Figure 2c). To provide functional evidence supporting the lipid desaturation-mediated effects of CAY10566, we measured sphere formation with exogenously added lipid supplementation. The combined addition of OA, which is a monounsaturated fatty acid synthesized by SCD1 [23], restored the suppression of sphere formation by CAY10566 (Figure 2c). These data supported SCD1 and lipid desaturation as major players in maintaining colon cancer spheroids.

a

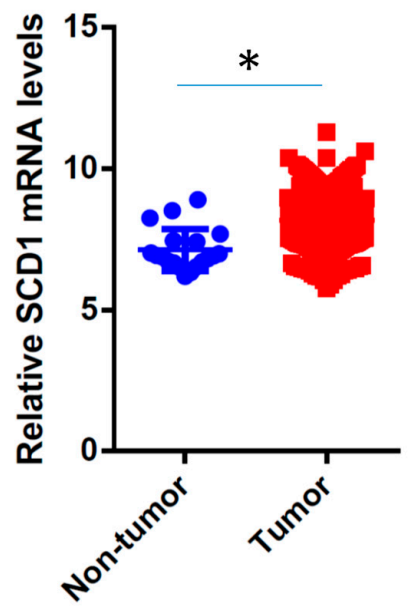

b

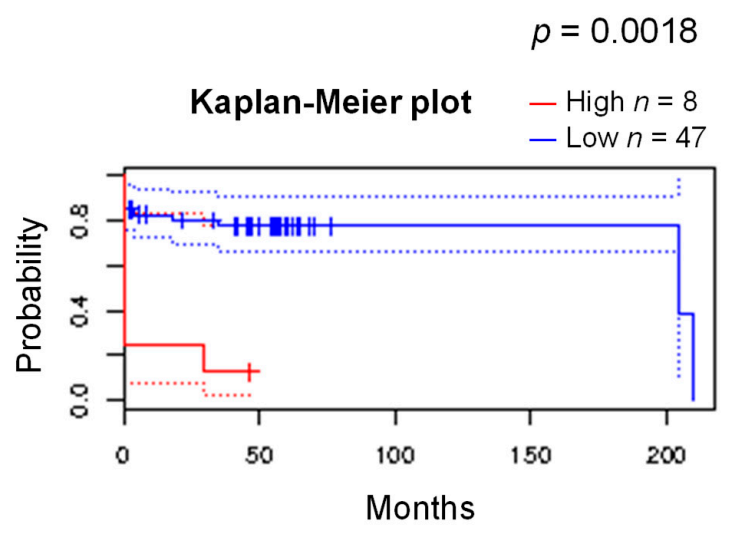

Figure 1. Clinical expression levels of stearoyl-CoA desaturase-1 (SCD1). (a) The expression of SCD1 mRNA in human colon cancer (right, $n=566$ ) and adjacent non-tumor tissues (left, $n=19$ ) (Gene Expression Omnibus (GEO) dataset GSE40967). Statistical significance was evaluated using the Mann-Whitney U test. ${ }^{*} p<0.05$. (b) The clinical significance of SCD1 expression in predicting the prognosis of colon cancer evaluated using the PrognoScan database analysis.

a

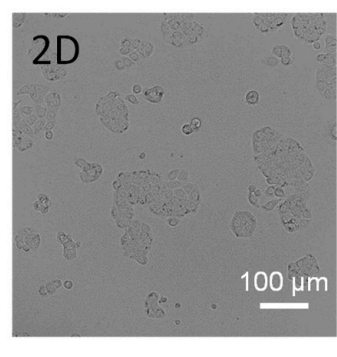

C

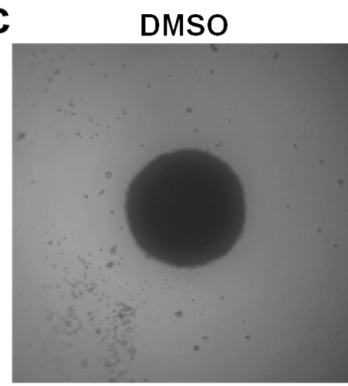

b
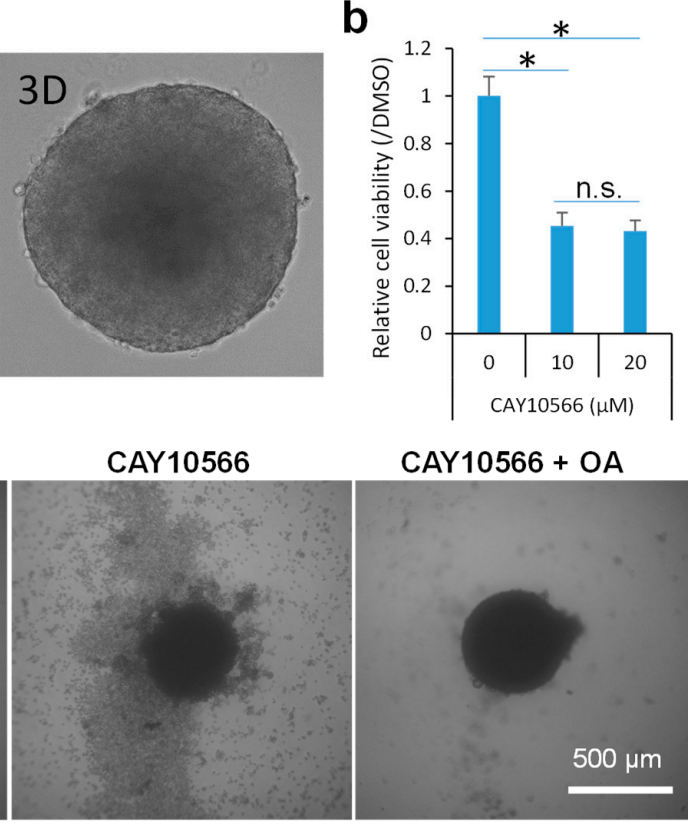

CAY10566 + OA

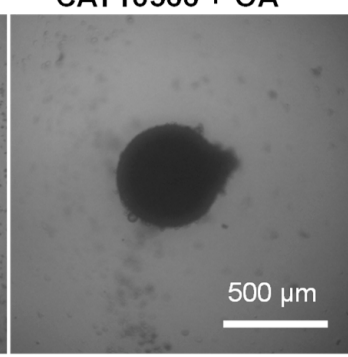

Figure 2. Inhibition of SCD1 suppresses colon cancer spheroid growth. (a) Representative microscopic images of WiDr cells grown as monolayers (left) and spheres (right). Scale bar, $100 \mu \mathrm{m}$. (b) Dose-dependent decrease in relative cell viability of WiDr cells grown as monolayers treated with increasing concentrations of a SCD1 inhibitor, CAY10566, for $48 \mathrm{~h}$. The data are presented as means ( $n=3$ replicates) $\pm \mathrm{SD} ;{ }^{*} p<0.05$, Student's $t$-test. n.s., not significant. (c) Representative microscopic images of WiDr cells grown as spheres treated with $20 \mu \mathrm{M}$ CAY10566 in the absence or presence of $100 \mu \mathrm{M}$ oleic acid (OA) for 3 days. Scale bar, $500 \mu \mathrm{m}$. 


\subsection{Inhibition of SCD1 Suppresses Myc Signaling in Colon Cancer Cells}

Finally, to gain more insight into the molecular basis for the role of SCD1 in human colon cancer, we identified the SCD1-correlated genes from the Cancer Genome Atlas (TCGA) database, which contains RNA-sequencing data from 382 colon tumor samples. With a threshold of Spearman's correlation coefficient of $>0.2,806$ genes were selected as SCD1-associated genes in human colon cancer (Figure 3a). To obtain direct and functional evidence regarding the correlation between SCD1 and its potential downstream targets in colon cancer cells, the effect of SCD1 knockdown on the expression of SCD1-correlated transcriptional regulators was examined using polymerase chain reaction (PCR) analysis. Transfection of WiDr cells with a pool of three target-specific siRNAs towards $S C D 1$ significantly suppressed the expression of sterol regulatory element-binding protein 2 (SREBP2; Figure $3 \mathrm{~b}$ ). The SCD1-correlated genes were imported into the Ingenuity Pathways Analysis (IPA) platform to investigate possible biological interactions. The diseases or functions annotation analysis showed that the genes involved in controlling lipid synthesis and incorporation, cell proliferation, and tissue tumorigenesis positively correlated with SCD1, while the genes regulating organismal death negatively correlated with SCD1 in human colon cancer (Figure 3c). Further network analysis of the biological functions of the top five IPA-generated networks are summarized in Figure 3d. The most highly populated biological networks entitled "Cancer, Organismal Injury and Abnormalities, Respiratory Disease" (Score $=45$ ) revealed a central role for Myc in the network hierarchy of the SCD1-correlated genes (Figure 3e).

a

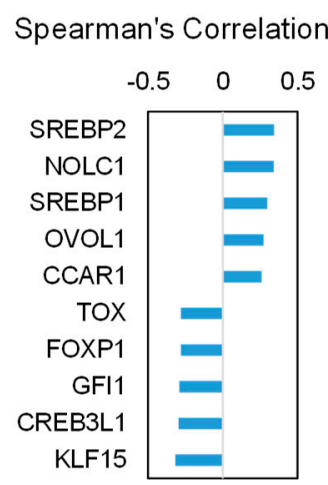

b

SCD1

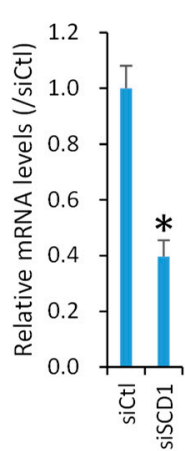

d

\begin{tabular}{cc}
\hline Top function & Score \\
\hline $\begin{array}{c}\text { Cancer, Organismal Injury and } \\
\text { Abnormalities, Respiratory Disease }\end{array}$ & 45 \\
\hline $\begin{array}{c}\text { Carbohydrate Metabolism, Small } \\
\text { Molecule Biochemistry, Cancer }\end{array}$ & 45 \\
\hline $\begin{array}{l}\text { Cell-To-Cell Signaling and Interaction, } \\
\text { Nervous System Development and } \\
\text { Function, Molecular Transport }\end{array}$ & 45 \\
\hline $\begin{array}{l}\text { Cell Death and Survival, Cellular Assembly } \\
\text { and Organization, DNA Replication, } \\
\text { Recombination, and Repair }\end{array}$ & 45 \\
\hline $\begin{array}{l}\text { Cellular Assembly and Organization, Hair } \\
\text { and Skin Development and Function, } \\
\text { Cellular Function and Maintenance }\end{array}$ & 43 \\
\hline
\end{tabular}

C SREBP2

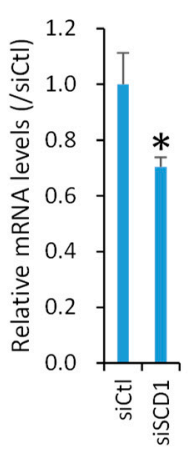

e

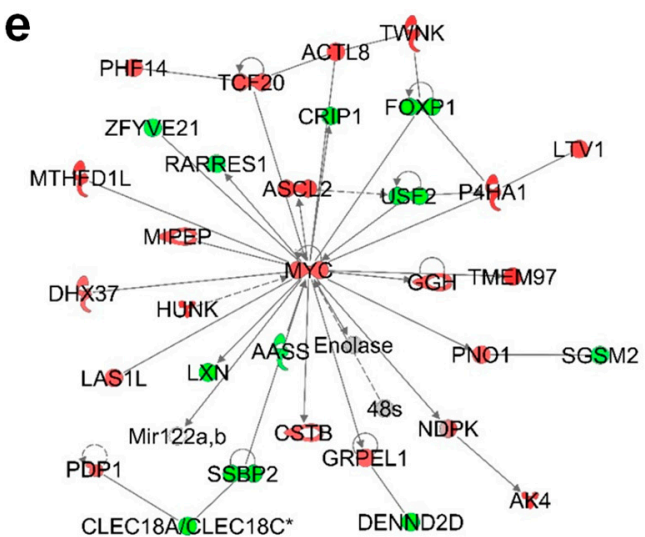

Figure 3. Inhibition of $S C D 1$ suppresses sterol regulatory element-binding protein 2 (SREBP) signaling. (a) The top transcription regulators correlated with SCD1 gene expression in human colon cancer selected through an analysis of the Cancer Genome Atlas (TCGA) database. The genes were ranked by Spearman's correlation coefficient. (b) The decrease in SCD1 (left) and SREBP2 (right) gene expression in WiDr cells grown as monolayers treated with $100 \mathrm{nM}$ siSCD1 for $24 \mathrm{~h}$. The data are presented as means 
( $n=3$ replicates) $\pm \mathrm{SD} .{ }^{*} p<0.05$, Student's $t$-test. (c) The top diseases or functions annotation associated with the 806 genes correlated with SCD1 in 382 human colon tumors (Spearman's correlation coefficient of more than 0.2) performed in the Ingenuity Pathways Analysis (IPA) platform. The pathways were ranked according to their activation $z$ score, which can be used to predict either the activated or inhibited state based on a statistically significant pattern match of up- and downregulation, respectively. (d) The top five associated network functions generated by the IPA platform. (e) A representative network related with Myc signaling entitled "Cancer, Organismal Injury and Abnormalities, Respiratory Disease".

\section{Discussion}

Our data show that SCD1 inhibition is an effective strategy for suppressing the spheroid growth of colon cancer cells. Mechanically, data mining in the TCGA database revealed that the master regulator of lipid homeostasis SREBP2 acted as a master transcription factor, whose gene expression positively correlated with SCD1 in human colon cancer. Importantly, siRNA knockdown of SCD1 significantly inhibited SREBP2 expression, suggesting that the anti-tumor effects of SCD1 inhibition are mediated, at least in part, through the downregulation of the SREBP signaling pathway. SREBP2 belongs to a family of transcription factors that regulate the expression of genes required for the synthesis of fatty acids, cholesterol, triacylglycerol, and phospholipid (Figure 4) [24]. Recently, the inhibition of SREBP has been shown to suppress tumor growth and initiation in colon cancer through the downregulation of cellular lipid biosynthesis [25]. Our data provide direct evidence that SREBP signaling is under the control of SCD1 in colon cancer cells.

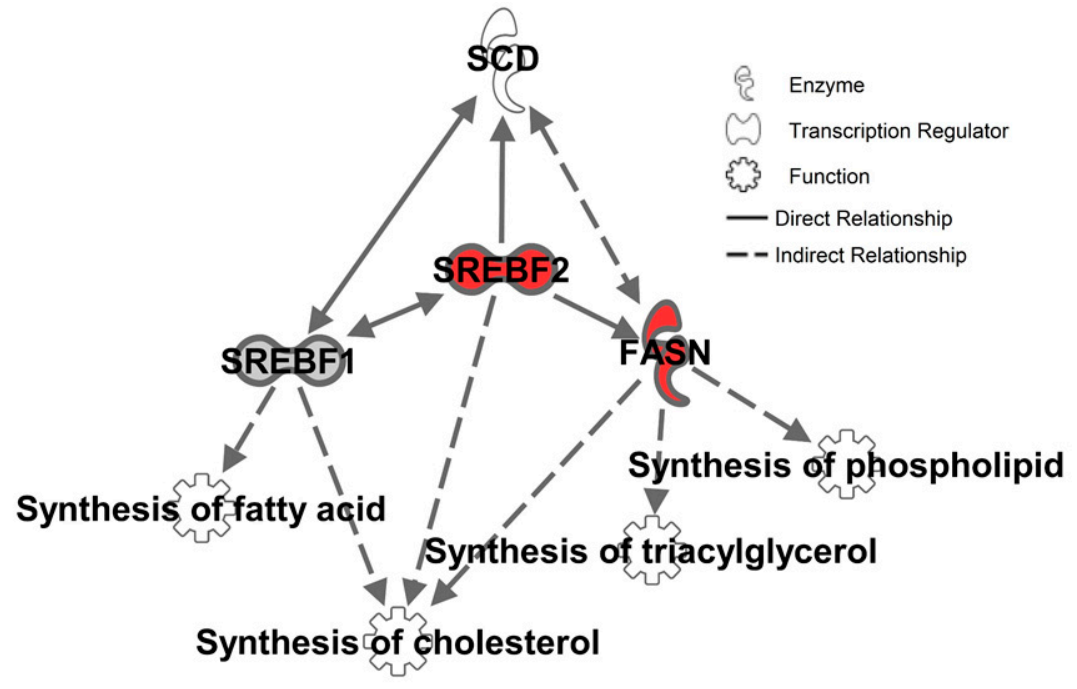

Figure 4. A schematic model of the SCD-dependent regulatory network in the control of lipid metabolism generated using the IPA platform. Red, genes whose expression were positively correlated with SCD1 gene expression in human colon cancer selected through an analysis of Cancer Genome Atlas (TCGA) database.

The pathway and network analyses suggested that the pro-tumorigenic effects of lipid desaturases, such as SCD1, in a human colon cancer cell lines are related to Myc signaling. Myc (c-Myc), a basic helix-loop-helix-zipper transcription factor, is reported as one of the Yamanaka factors [26] and plays a critical role in maintaining stem cell pluripotency. Myc also functions as an oncogene, contributing to both tumor initiation and maintenance by controlling cell growth [27]. A recent study has shown that $c-M y c$ activation positively regulates cell self-renewing and is indispensable for crypt regeneration and colon tumorigenesis [28]. Of interest, a domain-based interaction resource suggested a binding between human Myc and SCD1 proteins [29]. It has been reported that aberrant stabilization and dysregulated activation of Myc reprograms cancer cell metabolism to enhance precursor provisions for 
phospholipids [30]. In addition, OA administration partially rescues cell death-induced Myc signaling suppression, highlighting a critical role for lipid biosynthesis in Myc-driven cancer survival [30]. It seems plausible that there is a positive feedback loop between Myc activation and lipid metabolism reprograming, which is probably regulated by the phosphatase and tensin homolog (PTEN)/the mechanistic target of rapamycin (mTOR) signaling pathways [31,32].

In this study, we observed an increase in SCD1 gene expression in human colon cancer, which was significantly correlated with a poor prognosis. It has been reported that Toll-like receptor 4 (TLR4) deficiency can lead to the reduction of mRNA levels of genes involved in de novo lipogenesis, such as SCD1, but not genes involved in gluconeogenesis and fatty acid oxidation [33]. These data suggest that SCD1 expression might be regulated by the lipopolysaccharide (LPS)/TLR4 signaling pathways. Studies from the past few years demonstrate a strong impact of environmental factors, such as high-fat diet, on microbial composition and colon cancer risk [34]. Enhanced TLR4 expression in the intestinal epithelium has been shown to cause the expansion and proliferation of $\mathrm{Lgr}^{+}$colon stem cells [35]. Enhanced TLR4 expression in colon cancer is related to increased metastasis [36] and poor prognosis [37]. Therefore, it seems reasonable to hypothesize that increased SCD1 gene expression in colon cancer is controlled by microbial dysbiosis and the activation of TLR4 signaling.

\section{Materials and Methods}

\subsection{Cell Culture}

WiDr cell, derived from human colon adenocarcinoma cell line HT-29 [38], was maintained at $37{ }^{\circ} \mathrm{C}$ and $5 \% \mathrm{CO}_{2}$, in Dulbecco's modified Eagle medium (DMEM, Wako Industries, Osaka, Japan) containing 10\% fetal bovine serum (FBS; Mediatech, Herndon, VA, USA), $100 \mathrm{U} / \mathrm{mL}$ penicillin/streptomycin, and $2 \mathrm{mM} \mathrm{L-glutamine} \mathrm{(Mediatech).}$

\subsection{D Spheroid Culture and Chemical Treatment}

The cells were seeded onto non-adherent 96-well round-bottomed Sumilon PrimeSurface ${ }^{\mathrm{TM}}$ plates (MS-9096U, Sumitomo Bakelite, Tokyo, Japan) [20], in $100 \mu \mathrm{L}$ of media (DMEM plus 10\% FBS), at a concentration of 5000 cells per well. The spheroids were grown for 4 days, and then, $50 \mu \mathrm{L}$ of media were exchanged with $50 \mu \mathrm{L}$ fresh serum-free media containing $40 \mu \mathrm{M}$ CAY10566 (ab144421, Abcam, Cambridge, MA, USA), a SCD1 inhibitor, and/or $200 \mu \mathrm{M}$ OA (O1008, Sigma, Louis, MO, USA). The spheroids were further cultured for 3 days, and photos were taken using an optical microscope (DS-Fi1, NIKON, Tokyo, Japan). Dimethyl sulfoxide (DMSO, Sigma) was used as the primary solvent for all chemicals.

\subsection{Cell Viability Assay}

Cell viability was measured using a Cell Counting Kit-8 (Dojindo Molecular Technologies, Kumamoto, Japan). The absorbance was measured using a plate reader (ARVO MX, Perkin Elmer Inc., Waltham, MA, USA) at $450 \mathrm{~nm}$.

\subsection{In vitro RNA Interference}

A pool of 3 target-specific siRNAs targeting human SCD1 (sc-36464; siSCD1) and a control siRNA (sc-37007; siCtl) were purchased from Santa Cruz Biotechnology (Santa Cruz, CA, USA). WiDr cells were plated in 48-well plates for $24 \mathrm{~h}$ and then transfected with $100 \mathrm{nM}$ siRNAs using Lipofectamine 2000 transfection reagent (Life Technologies, Gaithersburg, MD, USA). On the following day, cells were collected for RNA isolation and further analysis.

\subsection{RNA Isolation and Real-time (RT)-PCR}

Total RNA was isolated using a FastGene RNA Basic Kit (FG-80250, NIPPON Genetics, Tokyo, Japan) and quantified using a NanoDrop spectrophotometer (NanoDrop products, Wilmington, 
DE, USA). cDNA was synthesized using a PrimeScript RT Master Mix Kit (TaKaRa Bio, Otsu, Japan). Primer sequences were as follows ( $5^{\prime}$ to $\left.3^{\prime}\right)$ : glyceraldehyde 3-phosphate dehydrogenase $(G A P D H)$ forward (CAATGACCCCTTCATTGACC) and reverse (GACAAGCTTCCCGTTCTCAG), SCD1 forward (GTACCGCTGGCACATCAACTT) and reverse (TTGGAGACTTTCTTCCGGTCAT), and SREBP2 forward (ATCGACCTAGGCAGTCTGGT) and reverse (ATAGAGGGCTTCCTGGCTCA). PCR reactions were performed using a Roche LightCycler 96 Real-Time PCR System (Roche Diagnostic Co., Ltd., Mannheim, Germany) and the SYBR Premix ExTaq II (TaKaRa Bio).

\subsection{Data Mining}

Normalized SCD1 expression from a clinical dataset, which contains transcriptome profiling of 566 colon cancer samples and 19 adjacent non-tumor samples, was downloaded from the GEO database (www.ncbi.nlm.nih.gov/geo, accession no. GSE40967) [21]. A PrognoScan database (http:/ / www.abren.net/PrognoScan/) analysis, which contains a large collection of publicly available cancer microarray datasets with clinical annotations, was conducted to investigate the clinical significance of SCD1 expression in predicting cancer prognosis [22].

\subsection{Knowledge-Based Pathway Analysis}

Genes correlated with $S C D 1$ gene expression in colon cancer were selected through an analysis of the TCGA database using cBioPortal software [39]. With a threshold of Spearman's correlation coefficient of $>0.2,806$ genes were selected and input into the knowledge-based functional analysis software IPA (Ingenuity Systems) as previously described [40]. The generated biological networks were ranked by score, which is the likelihood of a set of genes being found in the networks owing to random chance, identified by a Fisher's exact test. The generated diseases or functions annotations were ranked by the activation $z$-score, which can be used to find likely regulating molecules based on a statistically significant pattern match of up- and downregulation and also to predict the activation state (either activated or inhibited) of a putative regulator. An absolute $z$-score of more than 2 was considered to be significant.

\subsection{Statistical Analysis}

Quantitative data were expressed as the mean \pm SD of at least three replicates. The significance of differences between the values was assessed using Student's $t$-test or Mann-Whitney $U$ test. $p$-values of $<0.05$ were considered significant.

\section{Conclusions}

Our current findings suggest a potential role for unsaturated fatty acid-associated metabolic changes during colon tumorigenesis. Furthermore, lipid desaturases such as SCD1 might serve as therapeutic targets for colon cancer via the inhibition of SREBP-mediated lipid and cholesterol metabolism.

Author Contributions: Study conceptualization, X.-Y.Q. and S.K.; methodology/formal analysis/investigation, X.-Y.Q.; writing, X.-Y.Q. and S.K.; supervision, S.K.; and funding acquisition, X.-Y.Q. and S.K.

Acknowledgments: This work was supported by grants from the Ministry of Education, Culture, Sports, Science, and Technology of Japan Grant-in-Aid for Young Scientists (grant no. JP18K15833 to X.-Y.Q.), Grant-in-Aid for Scientific Research (C) (grant no. JP18K06976 to S.K.), a Research on the Innovative Development and the Practical Application of New Drugs for Hepatitis B Grant (grant no. JP17fk0310112) from the Japan Agency for Medical Research and Development (to S.K.), and the Takeda Science Foundation (to X.-Y.Q).

Conflicts of Interest: The authors declare no conflicts of interest. The funders had no role in the design of the study; in the collection, analyses, or interpretation of the data; in writing the manuscript; or in the decision to publish the results. 


\section{References}

1. Terzic, J.; Grivennikov, S.; Karin, E.; Karin, M. Inflammation and colon cancer. Gastroenterology 2010, 138, 2101-2114. [CrossRef] [PubMed]

2. Zeng, H.; Zheng, R.; Guo, Y.; Zhang, S.; Zou, X.; Wang, N.; Zhang, L.; Tang, J.; Chen, J.; Wei, K.; et al. Cancer survival in China, 2003-2005: A population-based study. Int. J. Cancer 2015, 136, 1921-1930. [CrossRef] [PubMed]

3. Varga, J.; Greten, F.R. Cell plasticity in epithelial homeostasis and tumorigenesis. Nat. Cell Biol. 2017, 19, 1133-1141. [CrossRef] [PubMed]

4. Barker, N.; van Es, J.H.; Kuipers, J.; Kujala, P.; van den Born, M.; Cozijnsen, M.; Haegebarth, A.; Korving, J.; Begthel, H.; Peters, P.J.; et al. Identification of stem cells in small intestine and colon by marker gene Lgr5. Nature 2007, 449, 1003-1007. [CrossRef] [PubMed]

5. Leung, C.; Tan, S.H.; Barker, N. Recent Advances in Lgr5(+) Stem Cell Research. Trends Cell Biol. 2018, 28, 380-391. [CrossRef] [PubMed]

6. O’Neill, A.M.; Burrington, C.M.; Gillaspie, E.A.; Lynch, D.T.; Horsman, M.J.; Greene, M.W. High-fat Western diet-induced obesity contributes to increased tumor growth in mouse models of human colon cancer. Nutr. Res. 2016, 36, 1325-1334. [CrossRef] [PubMed]

7. Beyaz, S.; Mana, M.D.; Roper, J.; Kedrin, D.; Saadatpour, A.; Hong, S.J.; Bauer-Rowe, K.E.; Xifaras, M.E.; Akkad, A.; Arias, E.; et al. High-fat diet enhances stemness and tumorigenicity of intestinal progenitors. Nature 2016, 531, 53-58. [CrossRef]

8. Karunanithi, S.; Levi, L.; DeVecchio, J.; Karagkounis, G.; Reizes, O.; Lathia, J.D.; Kalady, M.F.; Noy, N. RBP4-STRA6 Pathway Drives Cancer Stem Cell Maintenance and Mediates High-Fat Diet-Induced Colon Carcinogenesis. Stem Cell Reports 2017, 9, 438-450. [CrossRef]

9. Mihaylova, M.M.; Cheng, C.W.; Cao, A.Q.; Tripathi, S.; Mana, M.D.; Bauer-Rowe, K.E.; Abu-Remaileh, M.; Clavain, L.; Erdemir, A.; Lewis, C.A.; et al. Fasting Activates Fatty Acid Oxidation to Enhance Intestinal Stem Cell Function during Homeostasis and Aging. Cell Stem Cell 2018, 22, 769-778. [CrossRef]

10. Igal, R.A. Stearoyl-CoA desaturase-1: A novel key player in the mechanisms of cell proliferation, programmed cell death and transformation to cancer. Carcinogenesis 2010, 31, 1509-1515. [CrossRef]

11. Volmer, R.; van der Ploeg, K.; Ron, D. Membrane lipid saturation activates endoplasmic reticulum unfolded protein response transducers through their transmembrane domains. Proc. Natl. Acad Sci. USA 2013, 110, 4628-4633. [CrossRef] [PubMed]

12. Qin, X.Y.; Suzuki, H.; Honda, M.; Okada, H.; Kaneko, S.; Inoue, I.; Ebisui, E.; Hashimoto, K.; Carninci, P.; Kanki, K.; et al. Prevention of hepatocellular carcinoma by targeting MYCN-positive liver cancer stem cells with acyclic retinoid. Proc. Natl. Acad Sci. USA 2018, 115, 4969-4974. [CrossRef] [PubMed]

13. Qin, X.Y.; Dohmae, N.; Kojima, S. Reply to Yoshida: Liver cancer stem cells: Identification and lipid metabolic reprogramming. Proc. Natl. Acad Sci. USA 2018, 115, E6390-E6391. [CrossRef] [PubMed]

14. Li, J.; Condello, S.; Thomes-Pepin, J.; Ma, X.; Xia, Y.; Hurley, T.D.; Matei, D.; Cheng, J.X. Lipid Desaturation Is a Metabolic Marker and Therapeutic Target of Ovarian Cancer Stem Cells. Cell Stem Cell 2017, 20, 303-314. [CrossRef] [PubMed]

15. Lai, K.K.Y.; Kweon, S.M.; Chi, F.; Hwang, E.; Kabe, Y.; Higashiyama, R.; Qin, L.; Yan, R.; Wu, R.P.; Lai, K.; et al. Stearoyl-CoA Desaturase Promotes Liver Fibrosis and Tumor Development in Mice via a Wnt Positive-Signaling Loop by Stabilization of Low-Density Lipoprotein-Receptor-Related Proteins 5 and 6. Gastroenterology 2017, 152, 1477-1491. [CrossRef]

16. Ran, H.; Zhu, Y.; Deng, R.; Zhang, Q.; Liu, X.; Feng, M.; Zhong, J.; Lin, S.; Tong, X.; Su, Q. Stearoyl-CoA desaturase-1 promotes colorectal cancer metastasis in response to glucose by suppressing PTEN. J. Exp. Clin. Cancer Res. 2018, 37, 54. [CrossRef]

17. Chen, L.; Ren, J.; Yang, L.; Li, Y.; Fu, J.; Li, Y.; Tian, Y.; Qiu, F.; Liu, Z.; Qiu, Y. Stearoyl-CoA desaturase-1 mediated cell apoptosis in colorectal cancer by promoting ceramide synthesis. Sci. Rep. 2016, 6, 19665. [CrossRef]

18. Mason, P.; Liang, B.; Li, L.; Fremgen, T.; Murphy, E.; Quinn, A.; Madden, S.L.; Biemann, H.P.; Wang, B.; Cohen, A.; et al. SCD1 inhibition causes cancer cell death by depleting mono-unsaturated fatty acids. PLoS ONE 2012, 7, e33823. [CrossRef] 
19. Jung, H.R.; Kang, H.M.; Ryu, J.W.; Kim, D.S.; Noh, K.H.; Kim, E.S.; Lee, H.J.; Chung, K.S.; Cho, H.S.; Kim, N.S.; et al. Cell Spheroids with Enhanced Aggressiveness to Mimic Human Liver Cancer In Vitro and In Vivo. Sci. Rep. 2017, 7, 10499. [CrossRef]

20. Mikhail, A.S.; Eetezadi, S.; Allen, C. Multicellular tumor spheroids for evaluation of cytotoxicity and tumor growth inhibitory effects of nanomedicines in vitro: A comparison of docetaxel-loaded block copolymer micelles and Taxotere(R). PLoS ONE 2013, 8, e62630. [CrossRef]

21. Marisa, L.; de Reynies, A.; Duval, A.; Selves, J.; Gaub, M.P.; Vescovo, L.; Etienne-Grimaldi, M.C.; Schiappa, R.; Guenot, D.; Ayadi, M.; et al. Gene expression classification of colon cancer into molecular subtypes: Characterization, validation, and prognostic value. PLoS Med. 2013, 10, e1001453. [CrossRef]

22. Mizuno, H.; Kitada, K.; Nakai, K.; Sarai, A. PrognoScan: A new database for meta-analysis of the prognostic value of genes. BMC Med. Genomics 2009, 2, 18. [CrossRef] [PubMed]

23. Liu, J.; Cinar, R.; Xiong, K.; Godlewski, G.; Jourdan, T.; Lin, Y.; Ntambi, J.M.; Kunos, G. Monounsaturated fatty acids generated via stearoyl CoA desaturase-1 are endogenous inhibitors of fatty acid amide hydrolase. Proc. Natl. Acad Sci. USA 2013, 110, 18832-18837. [CrossRef] [PubMed]

24. Eberle, D.; Hegarty, B.; Bossard, P.; Ferre, P.; Foufelle, F. SREBP transcription factors: Master regulators of lipid homeostasis. Biochimie 2004, 86, 839-848. [CrossRef] [PubMed]

25. Wen, Y.A.; Xiong, X.; Zaytseva, Y.Y.; Napier, D.L.; Vallee, E.; Li, A.T.; Wang, C.; Weiss, H.L.; Evers, B.M.; Gao, T. Downregulation of SREBP inhibits tumor growth and initiation by altering cellular metabolism in colon cancer. Cell Death Dis. 2018, 9, 265. [CrossRef] [PubMed]

26. Takahashi, K.; Tanabe, K.; Ohnuki, M.; Narita, M.; Ichisaka, T.; Tomoda, K.; Yamanaka, S. Induction of pluripotent stem cells from adult human fibroblasts by defined factors. Cell 2007, 131, 861-872. [CrossRef] [PubMed]

27. Dang, C.V. MYC on the path to cancer. Cell 2012, 149, 22-35. [CrossRef]

28. Kim, M.J.; Xia, B.; Suh, H.N.; Lee, S.H.; Jun, S.; Lien, E.M.; Zhang, J.; Chen, K.; Park, J.I. PAF-Myc-Controlled Cell Stemness Is Required for Intestinal Regeneration and Tumorigenesis. Dev. Cell 2018, 44, 582-596. [CrossRef]

29. Miyamoto-Sato, E.; Fujimori, S.; Ishizaka, M.; Hirai, N.; Masuoka, K.; Saito, R.; Ozawa, Y.; Hino, K.; Washio, T.; Tomita, M.; et al. A comprehensive resource of interacting protein regions for refining human transcription factor networks. PLoS ONE 2010, 5, e9289. [CrossRef]

30. Carroll, P.A.; Diolaiti, D.; McFerrin, L.; Gu, H.; Djukovic, D.; Du, J.; Cheng, P.F.; Anderson, S.; Ulrich, M.; Hurley, J.B.; et al. Deregulated Myc requires MondoA/Mlx for metabolic reprogramming and tumorigenesis. Cancer Cell 2015, 27, 271-285. [CrossRef]

31. Masui, K.; Tanaka, K.; Akhavan, D.; Babic, I.; Gini, B.; Matsutani, T.; Iwanami, A.; Liu, F.; Villa, G.R.; Gu, Y.; et al. mTOR complex 2 controls glycolytic metabolism in glioblastoma through FoxO acetylation and upregulation of c-Myc. Cell Metab. 2013, 18, 726-739. [CrossRef] [PubMed]

32. Vinciguerra, M.; Veyrat-Durebex, C.; Moukil, M.A.; Rubbia-Brandt, L.; Rohner-Jeanrenaud, F.; Foti, M. PTEN down-regulation by unsaturated fatty acids triggers hepatic steatosis via an NF-kappaBp65/mTOR-dependent mechanism. Gastroenterology 2008, 134, 268-280. [CrossRef] [PubMed]

33. Jia, L.; Vianna, C.R.; Fukuda, M.; Berglund, E.D.; Liu, C.; Tao, C.; Sun, K.; Liu, T.; Harper, M.J.; Lee, C.E.; et al. Hepatocyte Toll-like receptor 4 regulates obesity-induced inflammation and insulin resistance. Nat. Commun. 2014, 5, 3878. [CrossRef] [PubMed]

34. Tilg, H.; Adolph, T.E.; Gerner, R.R.; Moschen, A.R. The Intestinal Microbiota in Colorectal Cancer. Cancer Cell 2018, 33, 954-964. [CrossRef] [PubMed]

35. Santaolalla, R.; Sussman, D.A.; Ruiz, J.R.; Davies, J.M.; Pastorini, C.; Espana, C.L.; Sotolongo, J.; Burlingame, O.; Bejarano, P.A.; Philip, S.; et al. TLR4 activates the beta-catenin pathway to cause intestinal neoplasia. PLoS ONE 2013, 8, e63298. [CrossRef] [PubMed]

36. Hsu, R.Y.; Chan, C.H.; Spicer, J.D.; Rousseau, M.C.; Giannias, B.; Rousseau, S.; Ferri, L.E. LPS-induced TLR4 signaling in human colorectal cancer cells increases beta1 integrin-mediated cell adhesion and liver metastasis. Cancer Res. 2011, 71, 1989-1998. [CrossRef] [PubMed]

37. Wang, E.L.; Qian, Z.R.; Nakasono, M.; Tanahashi, T.; Yoshimoto, K.; Bando, Y.; Kudo, E.; Shimada, M.; Sano, T. High expression of Toll-like receptor 4 /myeloid differentiation factor 88 signals correlates with poor prognosis in colorectal cancer. Br. J. Cancer 2010, 102, 908-915. [CrossRef] [PubMed] 
38. Chen, T.R.; Drabkowski, D.; Hay, R.J.; Macy, M.; Peterson, W., Jr. WiDr is a derivative of another colon adenocarcinoma cell line, HT-29. Cancer Genet. Cytogenet 1987, 27, 125-134. [CrossRef]

39. Cerami, E.; Gao, J.; Dogrusoz, U.; Gross, B.E.; Sumer, S.O.; Aksoy, B.A.; Jacobsen, A.; Byrne, C.J.; Heuer, M.L.; Larsson, E.; et al. The cBio cancer genomics portal: An open platform for exploring multidimensional cancer genomics data. Cancer Discov. 2012, 2, 401-404. [CrossRef]

40. Qin, X.Y.; Hara, M.; Arner, E.; Kawaguchi, Y.; Inoue, I.; Tatsukawa, H.; Furutani, Y.; Nagatsuma, K.; Matsuura, T.; Wei, F.; et al. Transcriptome Analysis Uncovers a Growth-Promoting Activity of Orosomucoid-1 on Hepatocytes. EBioMedicine 2017, 24, 257-266. [CrossRef]

(C) 2019 by the authors. Licensee MDPI, Basel, Switzerland. This article is an open access article distributed under the terms and conditions of the Creative Commons Attribution (CC BY) license (http:// creativecommons.org/licenses/by/4.0/). 